\title{
Task Sharing Chronic Disease Self-Management Training With Lay Health Coaches to Reduce Health Disparities
}

\author{
Sonal J. Patil, MD, MSPH \\ Department of Family and Community Medicine, University of Missouri, Columbia, Missouri \\ Ann Fam Med 2020;18:2-3. https://doi.org/10.1370/afm.2513.
}

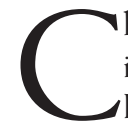

hronic disease self-management training improves health outcomes and reduces cost. ${ }^{1}$ However, one size does not fit all in self-management training interventions. Several factors, such as distance to self-management training program locations, educational level, and inequitable access to health care resources, affect utilization of these services in the minority and rural populations. ${ }^{2,3}$ Time constraints limit primary care physicians' abilities to care adequately for patients with multiple chronic illnesses. ${ }^{4}$ Lay health coaches can share tasks with clinic teams to provide selfmanagement training support in low-resource settings. ${ }^{5-8}$

Two articles in this issue of Annals of Family Medicine use lay health coach-delivered interventions to provide self-management training to disparate populations. The study by Andreae et al proposed to improve the functional status of rural adults with diabetes by targeting chronic pain for intervention, and Willard et al aimed to improve medication adherence in low-income urban populations with moderate to severe chronic obstructive pulmonary disease (COPD). ${ }^{9,10}$ Both studies included predominantly African American participants.

In a cluster-randomized controlled trial by Andreae et al, a 3-month, peer-delivered, telephoneadministered diabetes self-management program integrated cognitive behavioral therapy (CBT) principles to overcome pain as a barrier to physical activity in rural, low-income, predominantly female adult individuals with diabetes and chronic pain. The peer-delivered intervention improved function and pain subscales of Western Ontario and McMaster Universities Osteoarthritis Index (WOMAC) by 10 points, which represents

Conflict of interest: author reports none.

\section{CORRESPONDING AUTHOR}

Sonal J. Patil, MD, MSPH

Department of Family and Community Medicine

University of Missouri

MA306 Medical Sciences Building, DC032.00

Columbia, MO 65212

patilso@health.missouri.edu a meaningful improvement in patient symptoms. ${ }^{11}$ Selfreported physical activity also improved. Due to the short duration of the trial, likely, there was no improvement noted in physiologic measures.

The Andreae et al study's peer health coaches were adults affected by diabetes with previous training and experience in providing diabetes self-management support. They received an additional 30 hours of training in CBT components and activities. The intervention components are highly feasible for scaling up in a variety of rural settings as the use of a portable DVD player and telephone circumvents challenges of varying broadband and wireless connectivity in rural locations. ${ }^{12}$

Willard-Grace et al report secondary outcomes of medication adherence for the Aides in Respiration (AIR) health coaching study, a multisite randomized controlled trial of people living with COPD. ${ }^{13}$ Lay health coaches accompanied individuals with moderate to severe COPD from 7 urban county clinics serving low-income populations to primary care and specialist visits along with intermittent individual meetings and phone calls. Health coaches in Willard-Grace et al had a bachelor's degree and received 100 hours of training. At 9 months, health coaching intervention participants had a greater number of days of adherence to controller inhalers, increased likelihood of taking all medications as prescribed, and were 3 times as likely to demonstrate the perfect technique of all inhaler use. There was a significantly higher dropout rate in the intervention group compared to the usual care group (29\% vs $14 \%$ ), which may indicate a high intervention burden on participants.

Inhaler use technique was assessed in Willard-Grace et al by using standardized checklists where the patients were asked to demonstrate the use of inhalers. ${ }^{14}$ The teach-back technique requires approximately 5 minutes for Diskus devices and 8 minutes for metered-dose inhalers. ${ }^{15}$ Lay health coaches can be a valuable resource for teach-back techniques to improve self-management, self-monitoring, and medication adherence. ${ }^{16}$

In addition to assisting with the care navigation and patient education, lay health coaches can assist 
disparate populations by taking into account an individual's social context and focus on patient preferences for monitoring and self-management., $3,17,18$ The sustainability of lay health coach interventions in community settings beyond grant funding, however, is challenged by the lack of widespread reimbursements for these programs. ${ }^{19}$ Community coalitions targeting population health outcomes have been successful in promoting health equity by implementing policy and structural changes in deprived neighborhoods. ${ }^{20}$ There is a need for research that supports policy and payment models that integrate lay health coach programs to mitigate individual and familial social risks that impact chronic disease outcomes into primary care settings in socially deprived areas. ${ }^{21,22}$ Empowering primary care teams with advanced support in clinics is showing promise for improving patient and clinician satisfaction..$^{24}$ Lay health coaches can potentially "share-the-care" in communities, by assisting with the "work of being a patient" with chronic disease, to supplement primary-care visits in low-resource settings where "no moment is wasted."25-27

To read or post commentaries in response to this article, see it online at http://www.AnnFamMed.org/content/18/1/2.

Submitted December 2, 2019; accepted December 3, 2019.

Key words: lay health coaches; chronic disease; task-sharing; health disparity reduction chronic disease self-management, peer support

Acknowledgment: This work was supported by the National Center for Advancing Translational Sciences of the National Institutes of Health under Award Number KL2 TR002346.

Disclaimer: The content is solely the responsibility of the author and does not necessarily represent the official views of the National Institutes of Health.

\section{References}

1. Bodenheimer T, Lorig K, Holman H, Grumbach K. Patient selfmanagement of chronic disease in primary care. JAMA. 2002; 288(19):2469-2475.

2. Bobitt J, Aguayo L, Payne L, Jansen T, Schwingel A. Geographic and social factors associated with chronic disease self-management program participation: going the "extra-mile" for disease prevention. Prev Chronic Dis. 2019;16:E25-E25.

3. Brewer LC, Cooper LA, Patten CA. Diabetes self-management education for special populations: the social determinants of health matter. Public Health Rep. 2019;134(3):313-314.

4. Østbye T, Yarnall KS, Krause KM, Pollak KI, Gradison M, Michener $\mathrm{JL}$. Is there time for management of patients with chronic diseases in primary care? Ann Fam Med. 2005;3(3):209-214.

5. Ali MK, Echouffo-Tcheugui J, Williamson DF. How effective were lifestyle interventions in real-world settings that were modeled on the Diabetes Prevention Program? Health Aff (Millwood). 2012;31(1):67-75.

6. Kim K, Choi JS, Choi E, et al. Effects of community-based health worker interventions to improve chronic disease management and care among vulnerable populations: a systematic review. Am J Public Health. 2016;106(4):e3-e28.

7. Patil SJ, Lewis M, Tallon EM, et al. Lay advisor interventions in rural populations: a systematic review and meta-analysis. Am J Prev Med. 2019;57(1):117-126.
8. Patil SJ, Ruppar T, Koopman RJ, et al. Peer-support interventions for adults with diabetes: a meta-analysis of hemoglobin $A_{1 c}$ outcomes. Ann Fam Med. 2016;14(6):540-551.

9. Andreae SJ, Andreae LJ, Richman JS, Cherrington AL, Safford MM. Peer-delivered cognitive behavioral training to improve functioning in patients with diabetes: a cluster-randomized trial. Ann Fam Med. 2020;18(1):15-23.

10. Willard-Grace R, Chirinos C, Wolf J, et al. Lay health coaching to increase appropriate inhaler use in COPD: a randomized controlled trial. Ann Fam Med. 2020;18(1):5-14.

11. Tubach F, Ravaud P, Baron G, et al. Evaluation of clinically relevant changes in patient reported outcomes in knee and hip osteoarthritis: the minimal clinically important improvement. Ann Rheum Dis. 2005;64(1):29-33.

12. Bauerly BC, McCord RF, Hulkower R, Pepin D. Broadband access as a public health issue: the role of law in expanding broadband access and connecting underserved communities for better health outcomes. J Law Med Ethics. 2019;47(2_suppl):39-42.

13. Thom DH, Willard-Grace $R$, Tsao $S$, et al. Randomized controlled trial of health coaching for vulnerable patients with chronic obstructive pulmonary disease. Ann Am Thorac Soc. 2018;15(10):1159-1168.

14. Bodenheimer T. Teach-back: a simple technique to enhance patients' understanding. Fam Pract Manag. 2018;25(4):20-22.

15. Melani AS, Bonavia M, Mastropasqua E, et al; Gruppo Educazionale Associazione Italiana Pneumologi Ospedalieri (AIPO). Time required to rectify inhaler errors among experienced subjects with faulty technique. Respir Care. 2017;62(4):409-414.

16. Ha Dinh TT, Bonner A, Clark R, Ramsbotham J, Hines S. The effectiveness of the teach-back method on adherence and self-management in health education for people with chronic disease: a systematic review. JBI Database System Rev Implement Rep. 2016;14(1):210-247.

17. Kangovi S, Mitra N, Grande D, Huo H, Smith RA, Long JA. Community health worker support for disadvantaged patients with multiple chronic diseases: a randomized clinical trial. Am J Public Health. 2017;107(10):1660-1667.

18. Kangovi S, Mitra N, Norton L, et al. Effect of community health worker support on clinical outcomes of low-income patients across primary care facilities: a randomized clinical trial. JAMA Intern Med. 2018;178(12):1635-1643.

19. Kaufman A, Dickinson WP, Fagnan LJ, Duffy FD, Parchman ML, Rhyne RL. The role of health extension in practice transformation and community health improvement: lessons from 5 case studies. Ann Fam Med. 2019;17(Suppl 1):S67-S72.

20. Grumbach K, Vargas RA, Fleisher P, et al. Achieving health equity through community engagement in translating evidence to policy: the San Francisco Health Improvement Partnership, 2010-2016. Prev Chronic Dis. 2017;14:E27-E27.

21. DeVoe JE, Bazemore AW, Cottrell EK, et al. Perspectives in primary care: a conceptual framework and path for integrating social determinants of health into primary care practice. Ann Fam Med. 2016;14(2):104-108.

22. Huffstetler AN, Phillips RL Jr. Payment structures that support social care integration with clinical care: social deprivation indices and novel payment models. Am J Prev Med. 2019;57(6S1):S82-S88.

23. Pinto $A D$, Bloch $G$. Framework for building primary care capacity to address the social determinants of health. Can Fam Physician. 2017; 63(11):e476-e482.

24. Sinsky CA, Bodenheimer T. Powering-up primary care teams: Advanced team care with in-room support. Ann Fam Med. 2019;17(4):367-371.

25. Bodenheimer T. Anatomy and physiology of primary care teams. JAMA Intern Med. 2019;179(1):61-62.

26. Bolen SD, Sage P, Perzynski AT, Stange KC. No moment wasted: the primary-care visit for adults with diabetes and low socio-economic status. Prim Health Care Res Dev. 2016;17(1):18-32.

27. May C, Montori VM, Mair FS. We need minimally disruptive medicine. BMJ. 2009;339:b2803. 